\title{
Paramagnetic epoxy resin
}

\author{
E. C. Vázquez Barreiro, F. Fraga López ${ }^{*}$, A. Jover, F. Meijide, E. Rodríguez, J. Vázquez Tato
}

Facultad de Ciencias. Departamentos de Física Aplicada y Química Física. Campus de Lugo. Universidad de Santiago de Compostela, Avenida Alfonso X el Sabio S/N. 27002 Lugo, Spain

Received 11 July 2016; accepted in revised form 12 September 2016

\begin{abstract}
This work illustrates that macrocycles can be used as crosslinking agents for curing epoxy resins, provided that they have appropriate organic functionalities. As macrocycles can complex metal ions in their structure, this curing reaction allows for the introduction of that metal ion into the resin network. As a result, some characteristic physical properties of the metallomacrocycle could be transferred to the new material. The bisphenol A diglycidyl ether (BADGE, $n=0$ ) and hemin (a protoporphyrin IX containing the Fe(III) ion, and an additional chloride ligand) have been chosen. The new material has been characterized by differential scanning calorimetry (DSC), thermogravimetric analysis (TGA), Fourier Transform Infrared (FT-IR), Nuclear Magnetic Resonance (NMR), Transmission Electron Microscopy (TEM), and magnetic susceptibility measurements). $\mathrm{Fe}(\mathrm{III})$ remains in the high-spin state during the curing process and, consequently, the final material exhibits the magnetic characteristics of hemin. The loss of the chlorine atom ligand during the cure of the resin allows that $\mathrm{Fe}$ (III) can act as Lewis acid, catalyzing the crosslinking reactions. At high BADGE $n=0 /$ hemin ratios, the formation of ether and ester bonds occurs simultaneously during the process.
\end{abstract}

Keywords: thermosetting resins, hemin, epoxy resin, magnetic susceptibilit

\section{Introduction}

Cross-linked epoxy resins are nowadays standard options for a variety of applications due to their mechanical and thermal stabilities as well as their versatility [1]. The properties of a cured epoxy polymer depend on the type of epoxy resin and curing agent, as well as curing conditions. Epichlorohydrin and bisphenol A diglycidyl ether (e.g., BADGE, $n=0$ ) are among the most common epoxy monomers [2]. The epoxy ring can react with amines $[3,4]$ or carboxylic acids [5-8], among others. However searching for better mechanical and thermal properties, successfully achieved, has left other potential abilities of these systems almost unexplored.

By using transition metal complexes, with diamine derivatives as typical ligand in them, as controllable curing agents [9], metal ions have been incorporated into commercial epoxy resins, diamine derivatives being typical ligands in these complexes [10-12]. Dicarboxylate ferrocene has also been used [13]. Macrocycles can be used as crosslinking agents for curing the BADGE, $n=0$ epoxy resin, allowing for the introduction of a metal ion into the network structure, as we have recently demonstrated [14], hemin (a protoporphyrin IX containing the Fe(III) ion, and an additional chloride ligand) being used. As crosslinking agents, metallomacrocycles can offer the advantage of a complexed ion, while the organic functionalities of the macrocycle may be used for the curing process.

The aim of this work is to illustrate how the introduction of complexed Fe(III) ion into the network structure of the BADGE, $n=0$ resin transfers the magnetic properties of the ion to the new material.

Hemin has many potential applications as catalyst for reactions related to energy and environment, includ-

\footnotetext{
${ }^{*}$ Corresponding author, e-mail: francisco.fraga@usc.es C BME-PT
} 
ing the electrochemical reduction of uranium [15], nitrite [16, 17], nitric oxide [18-20], hydrogen peroxide [21], carbon dioxide [22], and oxidation of peroxynitrite [23]. Hemin is also able to catalyze the oxygen reduction reaction [24]. Platinum is the most widely used electrocatalyst in fuel cells of low temperature; however, its scarcity and high cost hinders the development of this technology. The metallomacrocycles, for example cobalt or iron porphyrins, have been considered as the most promising alternative, and has devoted a lot of work to improve their activity [25]. Hemin is an electrocatalyst with great potential for use in fuel cells or sensors that also are of great interest to many automakers and portable devices due to the high efficiency of energy conversion and low carbon dioxide emissions [26].

\section{Experimental}

The thermosetting system used consists of epoxy resin of bisphenol A diglycidyl ether, BADGE, $n=0$ (Resin 332 from Sigma Chemical Company, St. Louis, USA) with a molecular weight of $340.41 \mathrm{~g} / \mathrm{mol}$, and hemin (Fe (III) PPIX ) (Sigma Aldrich, St. Louis, USA) with a molecular weight of $651.94 \mathrm{~g} / \mathrm{mol}$. They are commercial products and were used without further purification. The resin was stored in a desiccator protected from light to prevent oxidation and carbonation while hemin was stored in the refrigerator at a temperature between $2-8^{\circ} \mathrm{C}$. The optimum molar ratio 6:1 (BADGE, $n=0 /$ hemin) have been used [14]. These compounds were carefully and homogeneously mixed at room temperature. For differential scanning calorimetry (DSC) the samples (about 8 to $10 \mathrm{mg}$ ) were introduced in aluminum pans on a DSCQ20, TA instruments, Eschborn, Germany. Measurements of thermogravimetric analysis (TGA) were performed on a TGA/DSC1 of Mettler Toledo, Columbus, Ohio, USA. FT-IR Analysis was performed on VARIAN FT-IR 670, Palo Alto, California, USA. Measurements of magnetic susceptibility were performed on a PPMS 6000 model PM90-L equipment (San Diego, USA) in the temperature range $2.3-292 \mathrm{~K}$ and in magnetic fields up to $9 \mathrm{~T}$. NMR analysis was performed on Varian Inova 750, Palo Alto, California, USA. TEM measurements were performed on a JEOL JEM-1011, Peabody, Massachusetts, USA.

\section{Results and discussion}

\subsection{Thermal analysis}

Reasons for choosing the molar ratio $6: 1$ as optimal rate for this system have been given elsewhere [14]. Additionally, the glass transition temperature $\left(T_{\mathrm{g}}\right)$ is also a function of the reaction stoichiometry. Obviously, different amounts of hemin involve different crosslinking densities. More linear structures (lower $T_{\mathrm{g}}$ ) are obtained for lower hemin contents, whereas higher hemin ratios are associated with an increase in $T_{\mathrm{g}}$. The highest $T_{\mathrm{g}}$ value is obtained for the $6: 1$ $(\mathrm{mol} / \mathrm{mol})$ molar ratio (Table 1) which supports the choosing of that ratio $6: 1$ as the optimal rate for this epoxy system.

TGA curves of the pure hemin and cured resin are shown in Figure 1. The samples suffered significant weight loss in the interval $0-900^{\circ} \mathrm{C}$, the shape of the curves being different for the two samples.

A simple profile is observed for the epoxy resin which decomposes at $336^{\circ} \mathrm{C}$ (results not shown) while the pure hemin shows a multistage decomposition profile with four weight loss steps, the temperature of each stage being clearly recognized. Weight loss per-

Table 1. Glass transition temperature for the different (BADGE, $n=0)$ /hemin molar ratio

\begin{tabular}{|c|c|}
\hline $\begin{array}{c}\text { (BADGE, } \boldsymbol{n}=\mathbf{0}) / \text { hemin } \\
\text { molar ratio }\end{array}$ & $\begin{array}{c}\boldsymbol{T}_{\mathbf{g}} \\
{\left[{ }^{\circ} \mathbf{C}\right]}\end{array}$ \\
\hline $4: 1$ & 106.9 \\
\hline $5: 1$ & 108.4 \\
\hline $6: 1$ & 109.8 \\
\hline $7: 1$ & 94.3 \\
\hline $8: 1$ & 99.6 \\
\hline $9: 1$ & 99.7 \\
\hline
\end{tabular}

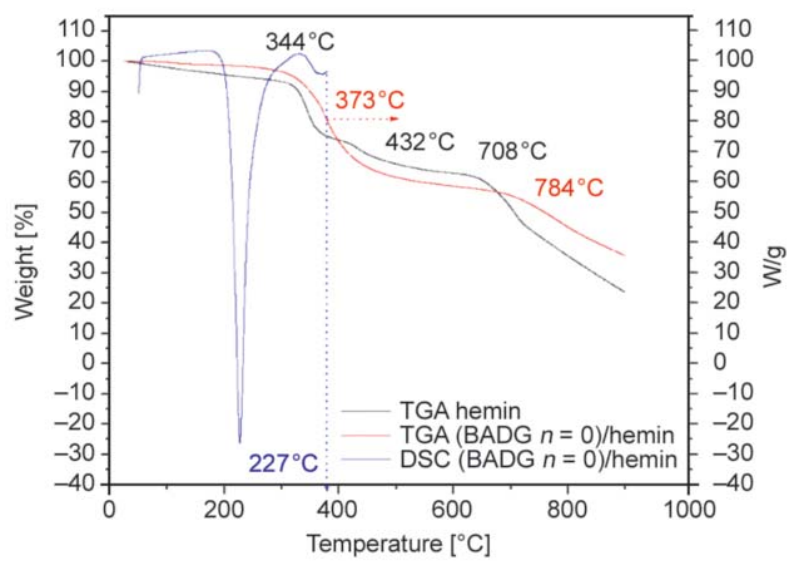

Figure 1. Thermogravimetric curves of the epoxy system (red line), hemin (black line) and DSC curve of the epoxy system (blue line). Heating rate of $10^{\circ} \mathrm{C} / \mathrm{min}$, under nitrogen flow $(50 \mathrm{ml} / \mathrm{min})$. 
centages of 5,15 , and $15 \%$ are observed at the interval of temperatures $150-300,330-440$, and 440$700{ }^{\circ} \mathrm{C}$, respectively. According to Liang et al. [26] the first stage weight loss can be attributed to the removal of the chlorine atom coordinated to the iron atom in the porphyrin ring. This loss, at the rather low temperature of $150{ }^{\circ} \mathrm{C}$, plays a very important role in this epoxy system since the Fe(III) can act as acid catalyst, thus promoting both reactions of esterification and etherification (see FTIR and NMR comments below).

The second stage corresponds primarily to the decomposition of the organic groups bound to the macrocycle, such as: $-\mathrm{CH}_{3},-\mathrm{CH}=\mathrm{CH}_{2}$, and $\mathrm{CH}_{2} \mathrm{CH}_{2} \mathrm{CO}_{2} \mathrm{H}$. The third stage is due to weight loss that occurs during the carbonization process of the hemin, including dehydrogenation and decomposition of the macrocycle. The weight loss from 700 to $800^{\circ} \mathrm{C}$ also is due to a partial loss of nitrogen atoms of the inner ring of hemin. However, there is a plateau between $500-700^{\circ} \mathrm{CC}$ where hemin retains the inner ring with 4 nitrogen atoms.

After curing, the epoxy-hemin system displays a different behaviour since the weight loss is found above $373{ }^{\circ} \mathrm{C}$. This temperature is in the middle of the interval of the second stage observed for hemin and suggests that the weight loss is probably associated to the decomposition of the same organic groups. This temperature is also close to the second signal (second minimum) of DSC thermograms (Figure 1). BADGE, $n=0$ starts to decompose around $300^{\circ} \mathrm{C}$, while an DSC endothermic signal at $348^{\circ} \mathrm{C}$ is observed for pure hemin (See Figures 2 and 3). None of these signals are in the thermogram of the mixture.

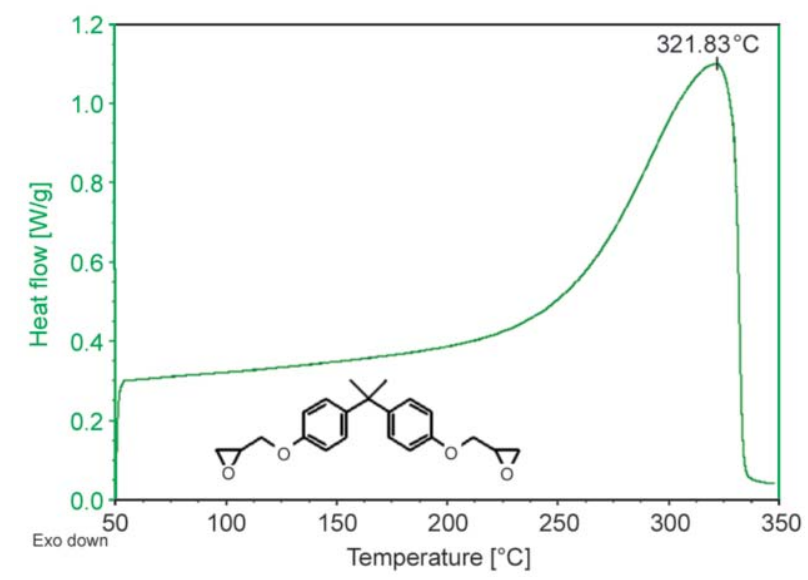

Figure 2. Dynamic experiment for the epoxy resin BADGE $n=0$

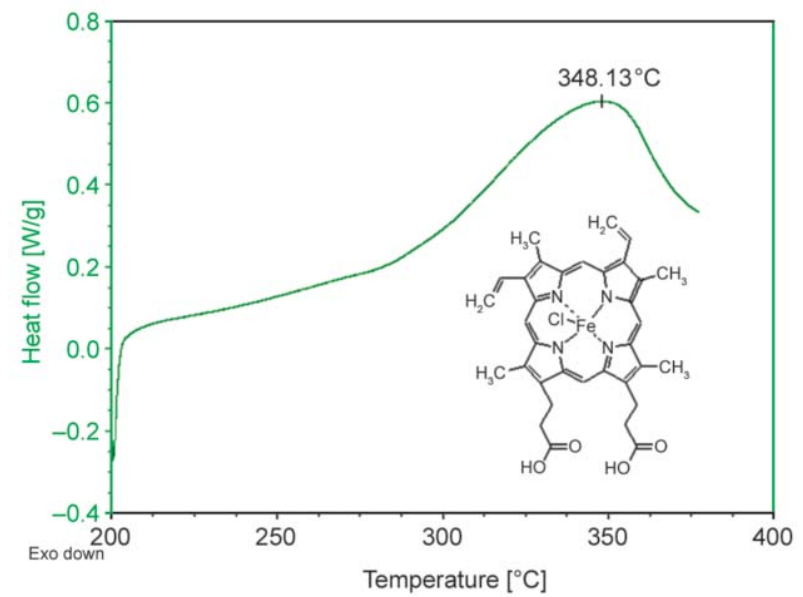

Figure 3. Dynamic experiment for the hemin

\subsection{Microscopic images}

Figure 4 shows TEM images for pure hemin where it can seen two phases: amorphous and other crystalline with rhombohedral structure and Figure 5 shows the TEM photographs of the material cured at $230^{\circ} \mathrm{C}$. Unreacted hemin crystals can be still seen on the crosslinked structure of the material.

Figure 6 shows the TEM images of the cured system at $380^{\circ} \mathrm{C}$, where the material begins to decompose. The network begins to release hemin due to the decomposition of the organic groups in the periphery of the ring.

\subsection{Infrared spectroscopy}

The IR spectrum of metalloporphyrins differs considerably from those of the corresponding porphyrins because the metal produces an increase in its symmetry and reduces the absorption bands. Most metalligand vibrations are in the far-infrared and depend on the metal. Table 2 shows the vibration bands of the pure hemin.

The band observed at $347 \mathrm{~cm}^{-1}$ for pure hemin (Figure 7), which corresponds to the vibration of the Fe$\mathrm{Cl}$ bond, disappears completely for the cured resin which indicates that the chlorine atom is liberated during the reaction in agreement with thermogravimetric analysis. Consequently, the Fe(III) can act as Lewis acid catalyzing the crosslinking reactions of the resin.

Figure 8 compares the FTIR spectra obtained for the epoxy system BADGE, $n=0 /$ hemin at different molar ratios of resin. All spectra are adjusted for the carbonyl signal. The most noticeable fact is that the signal at $1100 \mathrm{~cm}^{-1}$ (highlighted with an arrow), associ- 


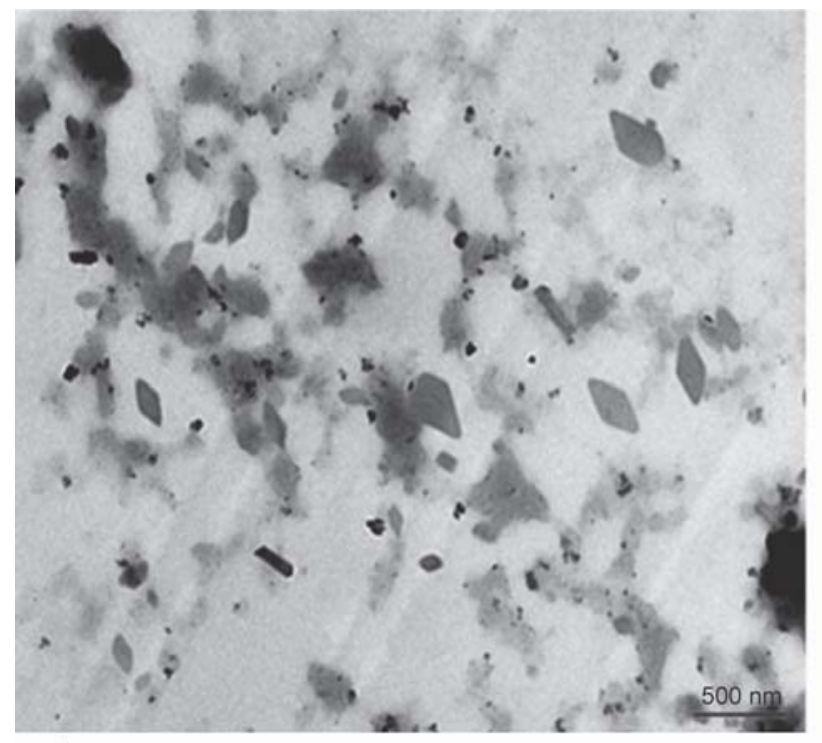

a)

Figure 4. TEM images of pure hemin a) $500 \mathrm{~nm}$, b) $100 \mathrm{~nm}$

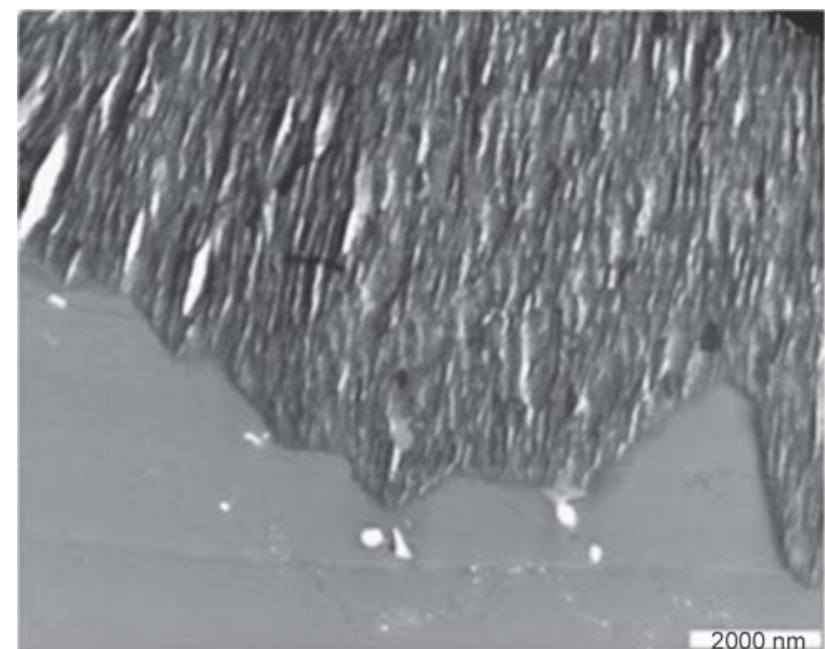

a)

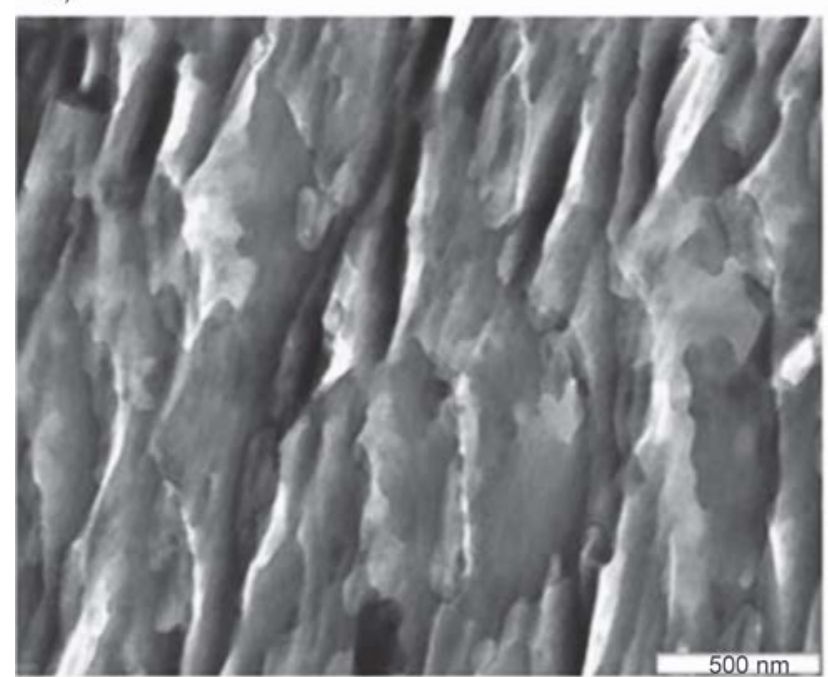

c)

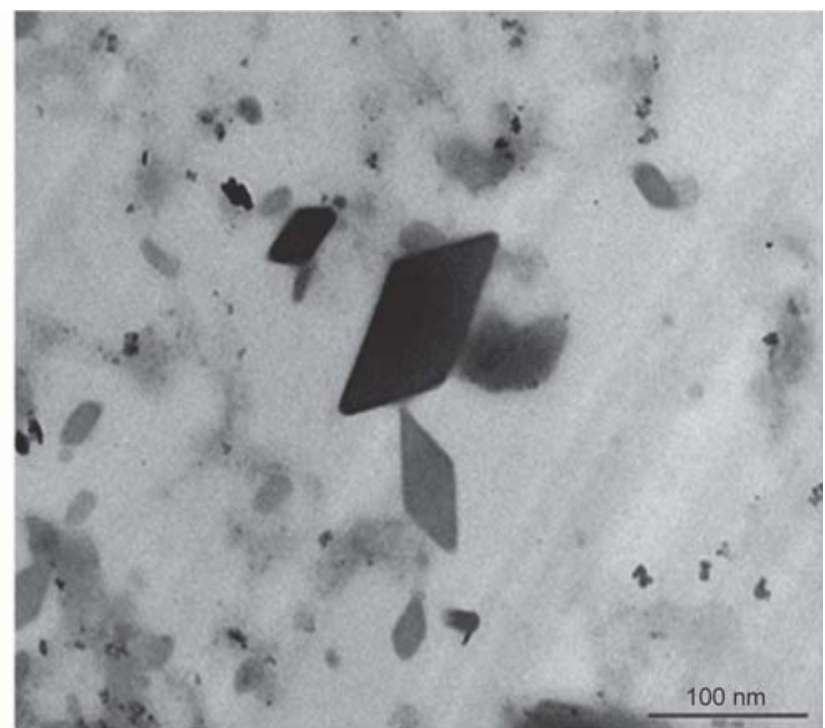

b)

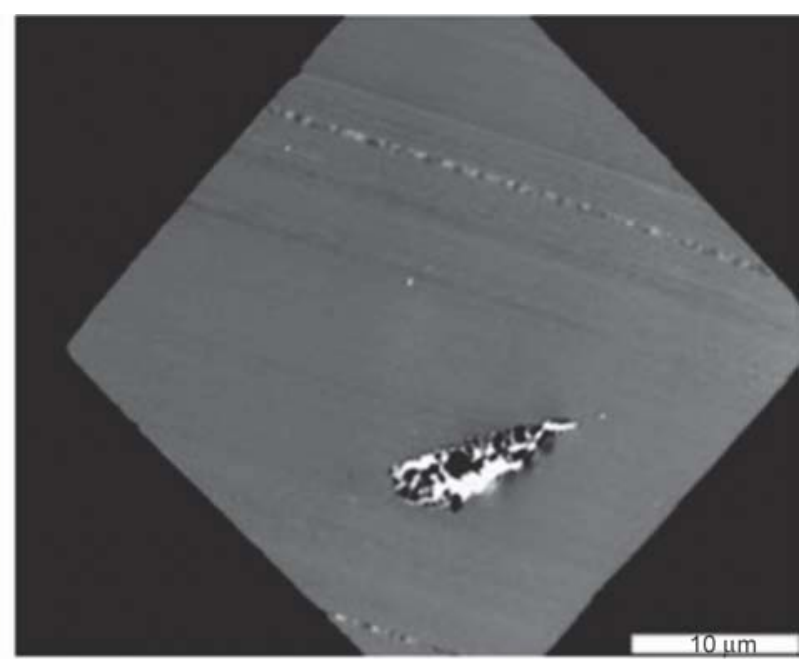

b)

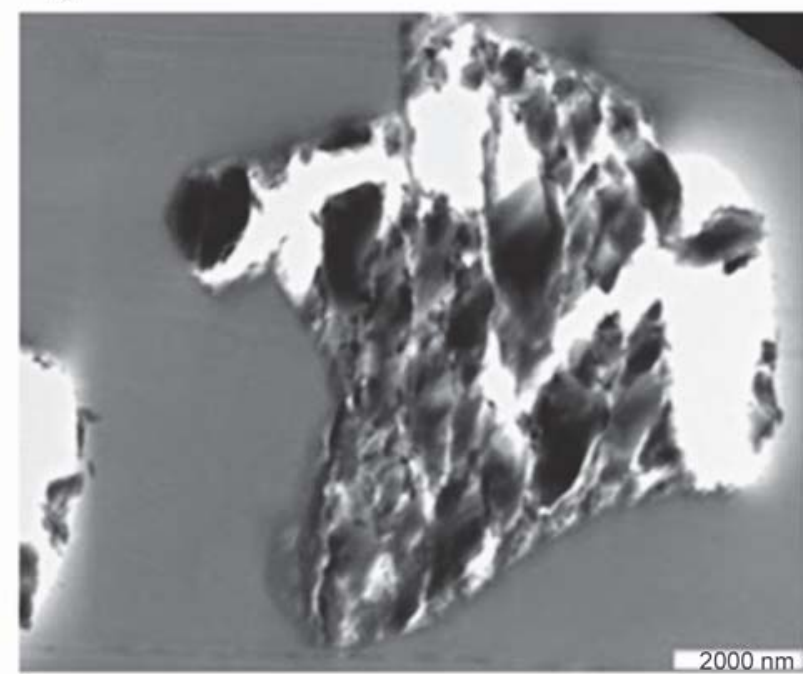

d)

Figure 5. TEM images of the epoxy sample cured until the temperature of $230^{\circ} \mathrm{C}$. Crossbar lengths: a) $2000 \mathrm{~nm}$, b) $10 \mu \mathrm{m}$, c) $500 \mathrm{~nm}$, d) $2000 \mathrm{~nm}$ 


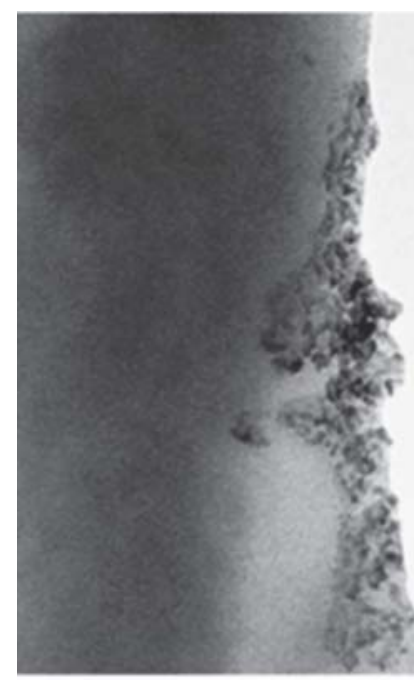

a)

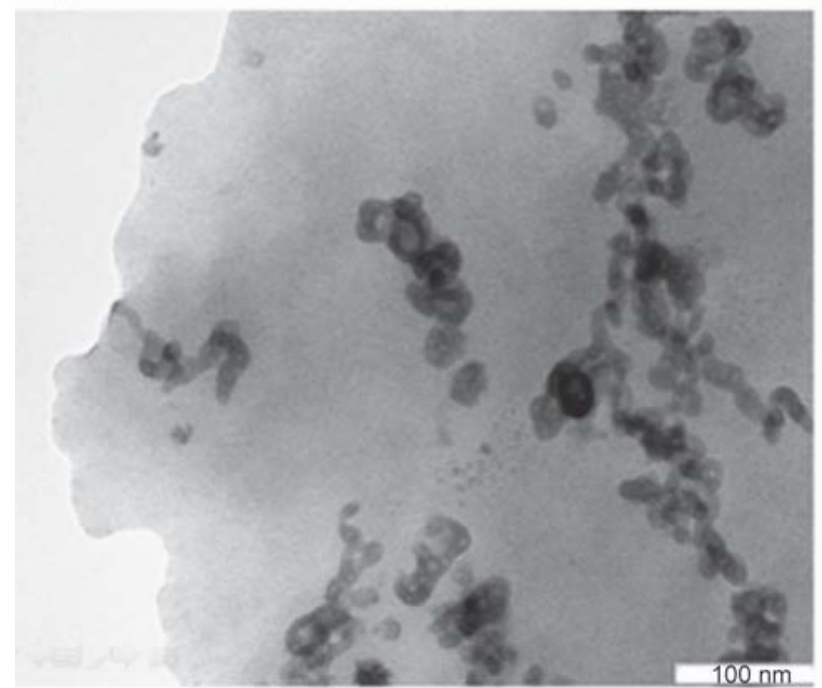

c)

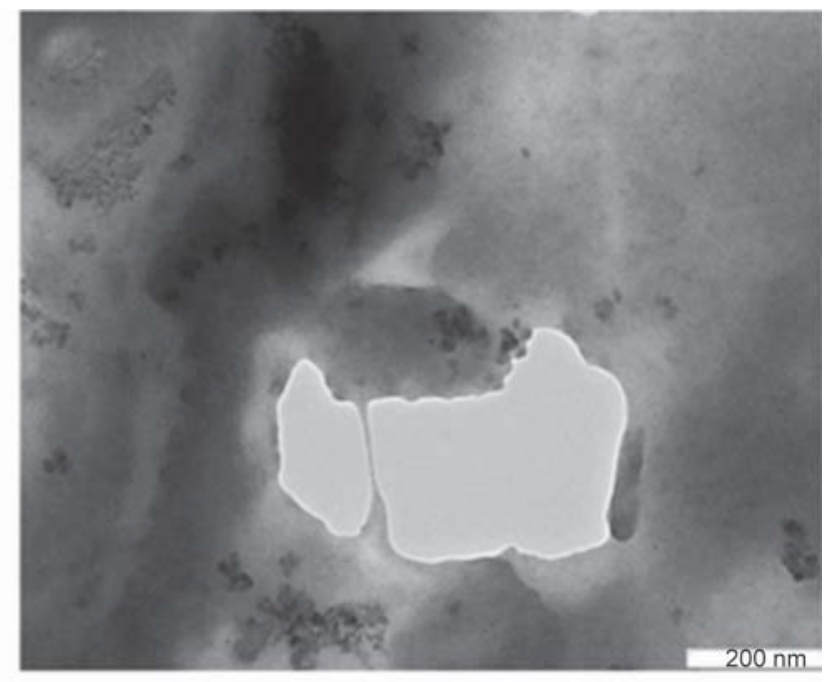

b)

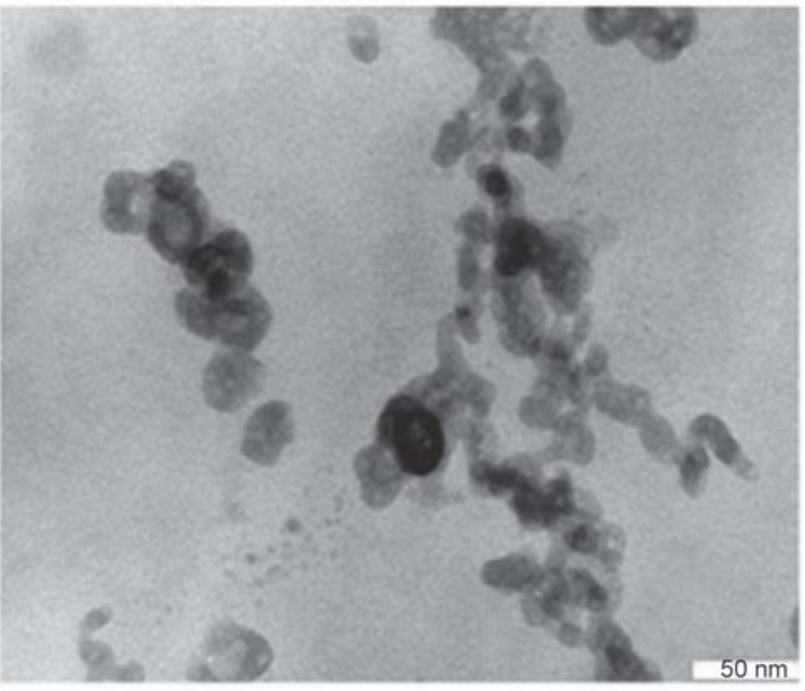

d)

Figure 6. TEM images of the epoxy sample cured until the temperature of $380^{\circ} \mathrm{C}$. Crossbar lengths: a) $100 \mathrm{~nm}$, b) $200 \mathrm{~nm}$, c) $100 \mathrm{~nm}$, and d) $50 \mathrm{~nm}$

Table 2. Vibration bands for the pure hemin

\begin{tabular}{|l|l|}
\hline \multicolumn{1}{|c|}{ Frequency } & \multicolumn{1}{c|}{ Vibration bands } \\
\hline$v_{\mathrm{OH}}:$ & For dimeric bonds is a broad band, usually centered on $3000 \mathrm{~cm}^{-1}$ \\
$3300-2500 \mathrm{~cm}^{-1}$ & Shoulders \\
$2700-2500 \mathrm{~cm}^{-1}$ & There is a thin band for free species \\
$3580-3500 \mathrm{~cm}^{-1}$ & Dimeric bonds of saturated carboxylic acids \\
\hline$v_{\mathrm{C}=\mathrm{O}}:$ & These vibrations are coupled in acids resulting in two bands at $1440-1210 \mathrm{~cm}^{-1}$ \\
$1725-1680 \mathrm{~cm}^{-1}$ & $\delta_{\mathrm{OH}}$ \\
\hline$\delta_{\mathrm{OH}}+v_{\mathrm{C}-\mathrm{O}}:$ & $v_{\mathrm{C}-\mathrm{O}}$ \\
$1440-1395 \mathrm{~cm}^{-1}$ & \\
$1315-1210 \mathrm{~cm}^{-1}$ & Vibrational motion out of the plane of the hydrogens \\
\hline$\gamma_{\mathrm{OH}}:$ & Vibrational motion of $\mathrm{N}-\mathrm{Fe}$ \\
\hline $960-880 \mathrm{~cm}^{-1}$ & CH bond of the pyrrole \\
\hline$\gamma_{\mathrm{N}-\mathrm{Fe}}:$ & Vibrational motion of $\mathrm{Fe}-\mathrm{Cl}$ \\
$989 \mathrm{~cm}^{-1}$ & \\
\hline$\gamma_{\mathrm{C}-\mathrm{H}:}$ & \\
$770-710 \mathrm{~cm}^{-1}$ & \\
\hline$\gamma_{\mathrm{Fe}-\mathrm{Cl}:}:-1$ & \\
$347 \mathrm{~cm}^{-1}$ &
\end{tabular}




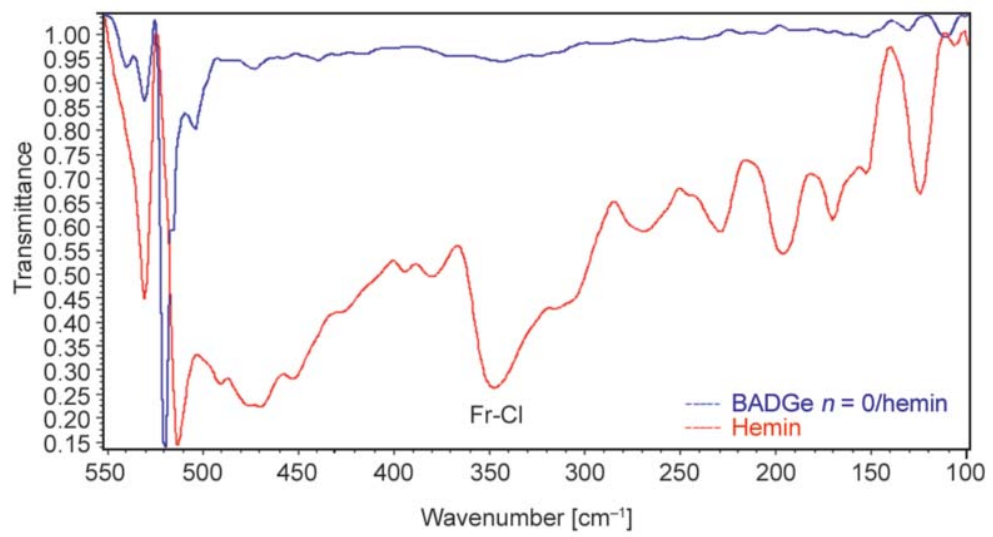

Figure 7. Far-infrared spectra of the hemin (red line) and the epoxy system BADGE, $n=0 /$ hemin (blue line)

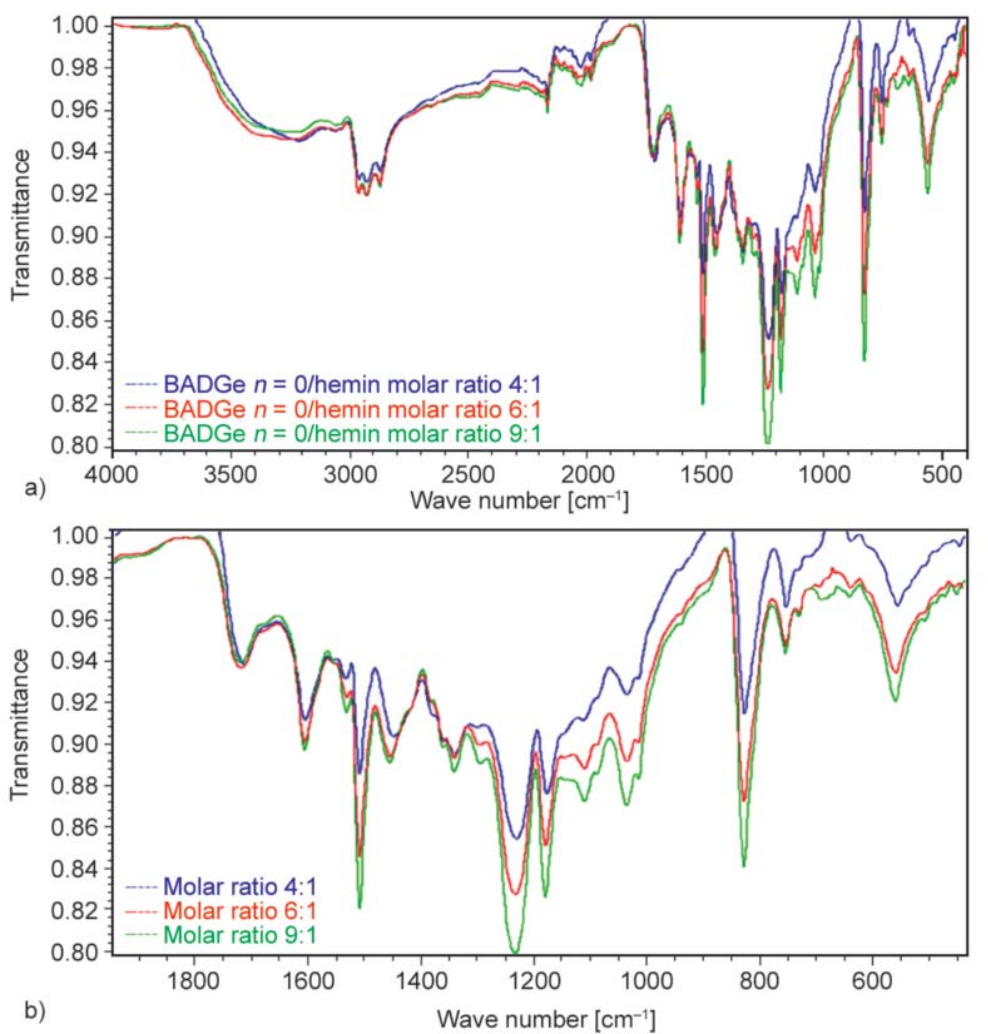

Figure 8. a) FTIR spectra of the epoxy system BADGE, $n=0 /$ hemin for different molar ratios epoxy/hemin. b) Zoom of the Figure (a) in the range $1950-450 \mathrm{~cm}^{-1}$.

ated with $\mathrm{C}-\mathrm{O}-\mathrm{C}$ aliphatic ethers, neither appears in the uncured resin nor in the cured resin at the ratio of 4:1. However its intensity grows with the increase of this ratio. It may be concluded that at high temperatures and molar ratios above 6:1, a epoxy-hydroxyl reaction occurs (i.e., etherification; Figure 9) which is responsible for the asymmetrical dynamic shoulder observed in DSC experiments (Figure 10). However it is present for the ratio 6:1 and it is even more intense for the ratio 9:1. This confirms that the appearance of the asymmetric shoulder in the thermograms of samples with excess epoxy is due to the etherification reaction (Figure 9a) [14]. The signals at
1610 and $1510 \mathrm{~cm}^{-1}$, assigned to the $\mathrm{C}=\mathrm{C}$ and $\mathrm{C}-\mathrm{C}$ bonds of benzene rings of the resin, do not exhibit significant changes during the polymerization although they increase with the proportion of resin. Similar comments apply to bands in the range of $2965-2873 \mathrm{~cm}^{-1}$ which are due to the stretching vibration of $\mathrm{C}-\mathrm{H}$ in the methylene groups and to the stretching vibration of aromatic and aliphatic $\mathrm{CH}$.

Figure 11 shows a significant increase of the transmittance at $3450 \mathrm{~cm}^{-1}$ that can be assigned to the hydroxyl groups formed during the polymerization. This increase is accompanied by a decrease in intensity at $915 \mathrm{~cm}^{-1}$, assigned to the signal of epoxy 


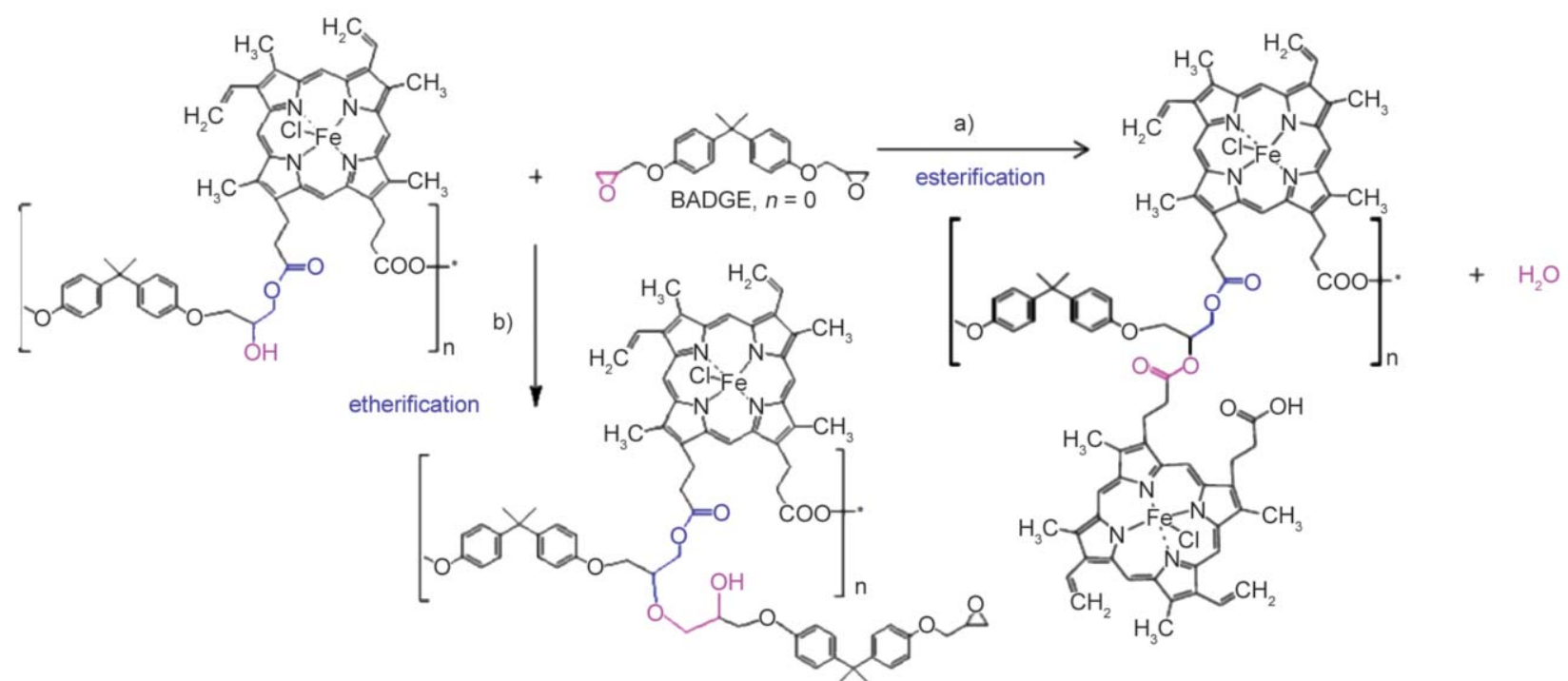

Figure 9. Reactions for the epoxy system BADGE, $n=0$ /hemin: (a) esterification and (b) etherification

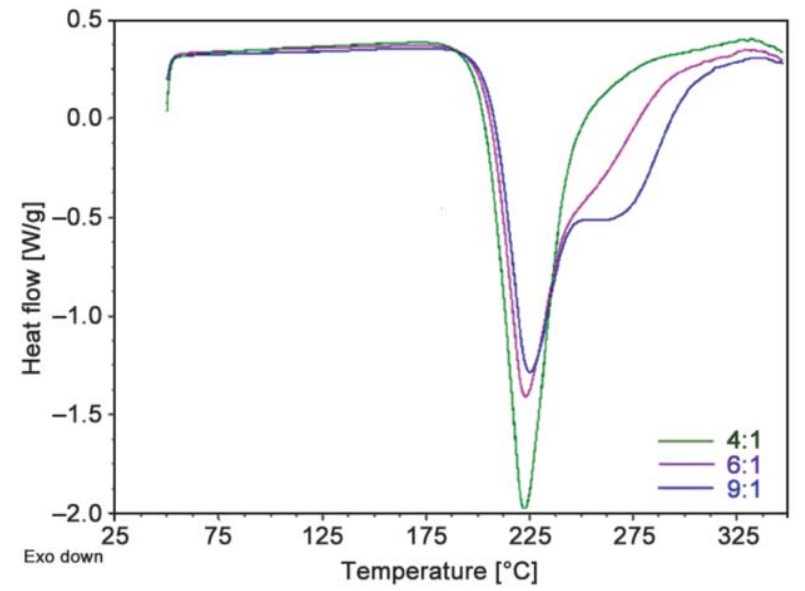

Figure 10. Dynamic experiments of the epoxy system at different (BADGE, $n=0) /$ hemin ratios, $n: 1(n=4,6$ and 9)

groups. The intense band of the pure hemin at $1698 \mathrm{~cm}^{-1}$, corresponding to the carboxylic acids, decreases while a new band at $1719 \mathrm{~cm}^{-1}$, associated with the formation of ester groups, increases.

\subsection{Kinetic studies}

In a previous paper [14] we have calculated the kinetic parameters using Kamal model. This model is used for describing the isothermal experiments, but the statistical criteria do not allow setting exact power exponents. In recent years, the use of Kamal model for kinetic studies has been the object of a wide discussion [27-33]. Besides, the overall reaction order varies over a wide range [27, 34-35]. Vyazovkin and Sbirrazzuoli have proposed that isoconversional methods are most appropriate to describe the complex curing kinetics. Furthermore, the isoconversional method does not require the knowledge of the rate equation $f(\alpha)$, as it only assumes that for a given degree of conversion, $\alpha$, the reaction process has the same mechanism, independently of the curing temperature. The isoconversional method can determine the activation energy for each degree of conversion, allowing to check whether the activation energy is kept constant for the curing reaction.

Dell'Erba and Williams [36] have proposed that the consumption of the epoxy groups can be expressed by the following phenomenological Equation (1):

$$
\frac{\mathrm{d} x}{\mathrm{~d} t}=k f(x)=A \exp \left(-\frac{E}{R T}\right) f(x)
$$

where $x$ is the conversion of epoxy groups, $t$ is the time, $k$ is a parameter which depends of temperature, and $E$ is the activation energy.

The time required to reach a particular conversion at a given temperature can be obtained by the Equation (2):

$$
\ln t_{\mathrm{x}}=\ln A^{-1}+\ln F(x)+\frac{E}{R T}
$$

where $F(x)=\int_{0}^{\mathrm{x}} f(x)^{-1} \mathrm{~d} x$ is an unknown function that depends only on the conversion. Therefore, a set of parallel lines should be obtained when plotting $\ln t_{\mathrm{x}}$ versus $T^{-1}$ for different conversions. Figure 12 shows the isotherm data at the interval $130-160^{\circ} \mathrm{C}$, confirming the validity of Equation (2) for the BADGE, $n=$ $0 /$ hemin system. The activation energy calculated from the slope of the lines is $95 \pm 7 \mathrm{~kJ} / \mathrm{mol}$. This value is close to the obtained previously [14] by Kamal kinetic method and, consequently, it can be accepted 

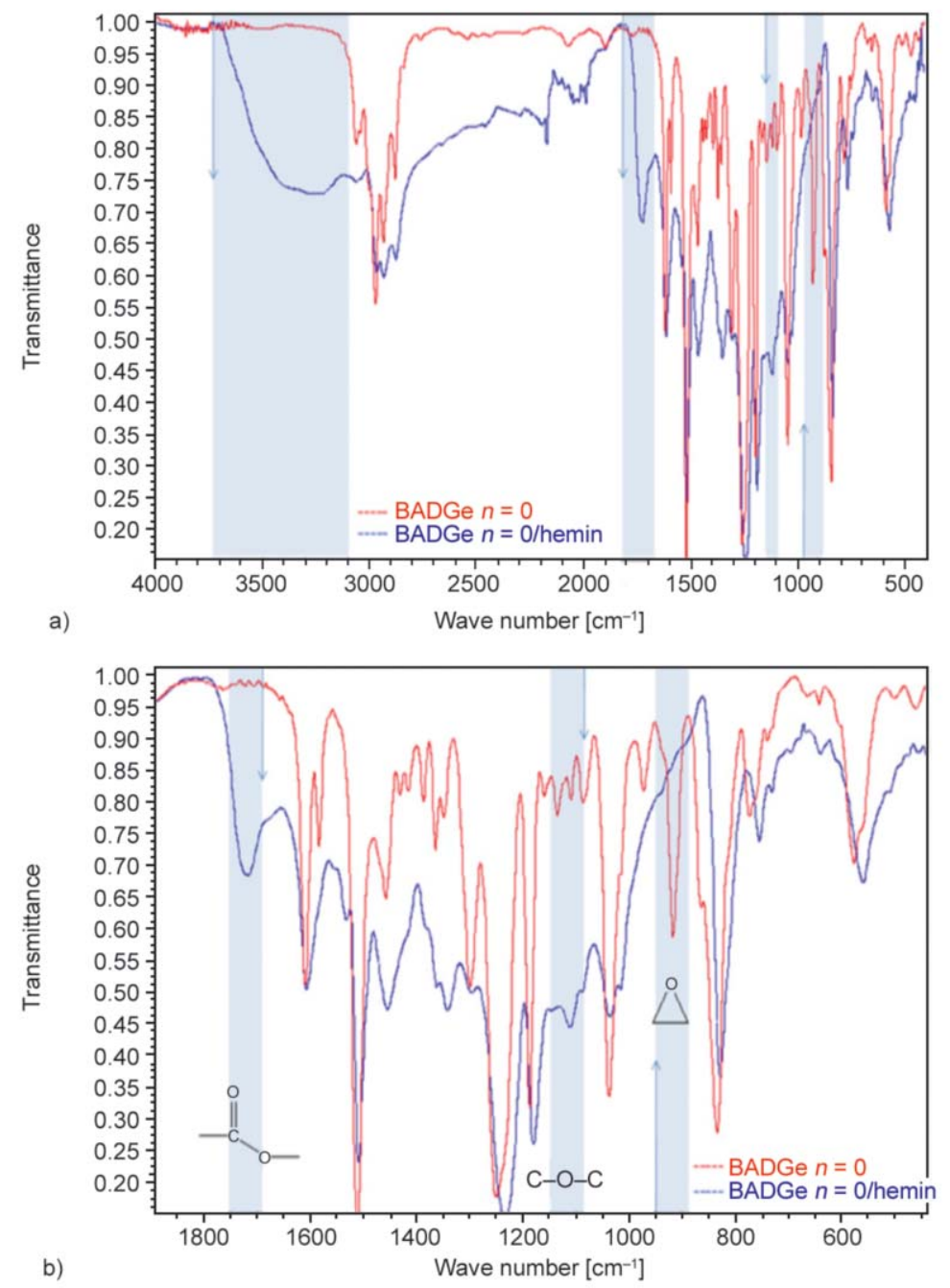

Figure 11. a) FTIR spectra of the epoxy system at 6:1 (BADGE, $n=0$ )/hemin) ratio. As reference, the FTIR spectrum of BADGE, $n=0$ is also shown. b) Zoom of the Figure (a) in the range $1900-450 \mathrm{~cm}^{-1}$.

that this model adequately represents the kinetic behavior of this system.

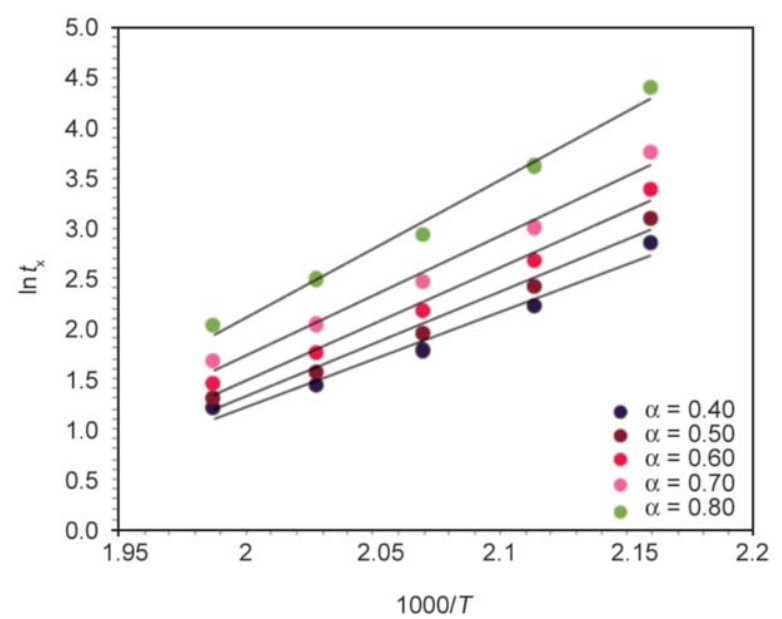

Figure 12. Isoconversional method for the system BADGE $n=0 /$ hemin

\subsection{Magnetic measurements}

It has been shown that the nature of the ligand affects the electronic state of the five d electrons in $\mathrm{Fe}(\mathrm{III})$ complexes [37] and, depending on the ligand, energy ordering of the various electronic states of Fe(III) complexes can change. With strong field ligands (e. g., cyanide) $d$ electrons are in a low-spin configuration ${ }^{2} \mathrm{~T}_{2 \mathrm{~g}}(S=1 / 2)$, while weak field ligands (e.g. chloride, fluoride or water) cause the $d$ electrons remain unpaired in ${ }^{6} \mathrm{~A} 1_{\mathrm{g}}$ high-spin state $(S=5 / 2)$. In a pyridine-chloroform mixture, dissolved hemin is in a thermal equilibrium between low- and high-spin states $[38,39]$, while solid hemin is mostly in the high-spin one [40]. State spin influences binding affinity and the connecting structure between $\mathrm{Fe}(\mathrm{III})$ and the porphyrin ring. The difference between a low and high spin states is also important from the point of view of their biological functions. 


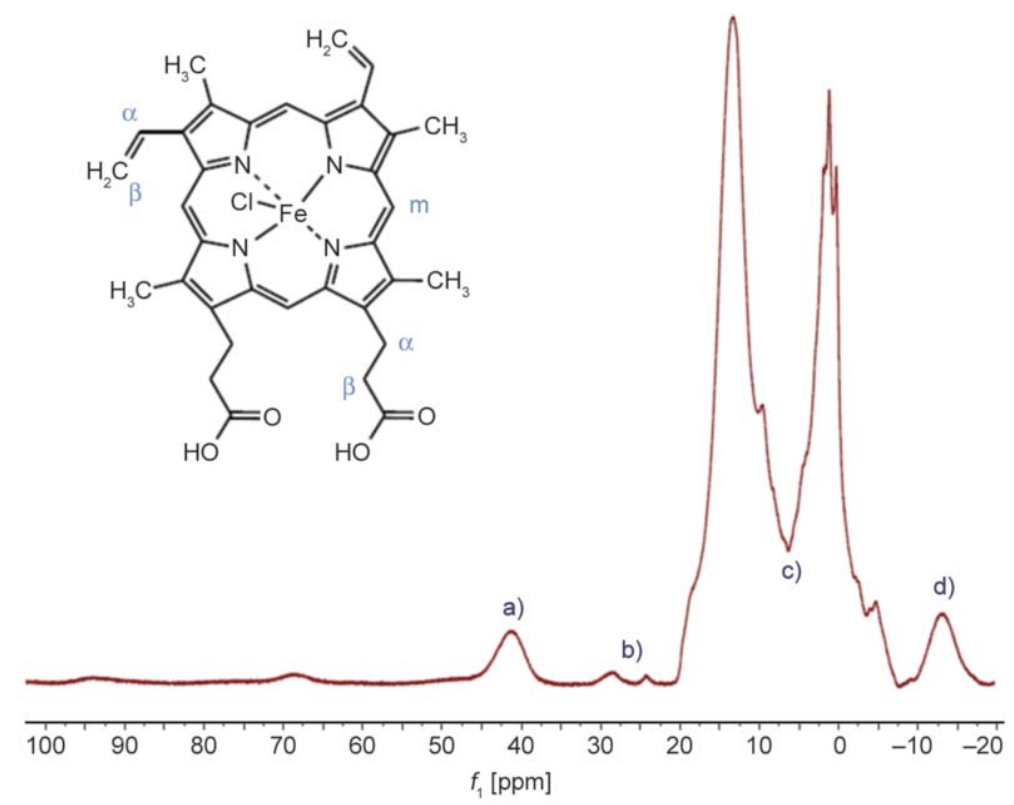

Figure 13. ${ }^{1} \mathrm{H}$ NMR spectrum (HDQfilter) of hemin. Tentative assignments of peaks are: a) methyl groups, b) vinyl $\alpha$-CH and propionyl $\alpha-\mathrm{CH}_{2}$ and c) cis and trans vinyl $\beta-\mathrm{CH}_{2}$ and propionyl $\beta-\mathrm{CH}_{2}$ peaks and d) signals for the porphyrin meso protons

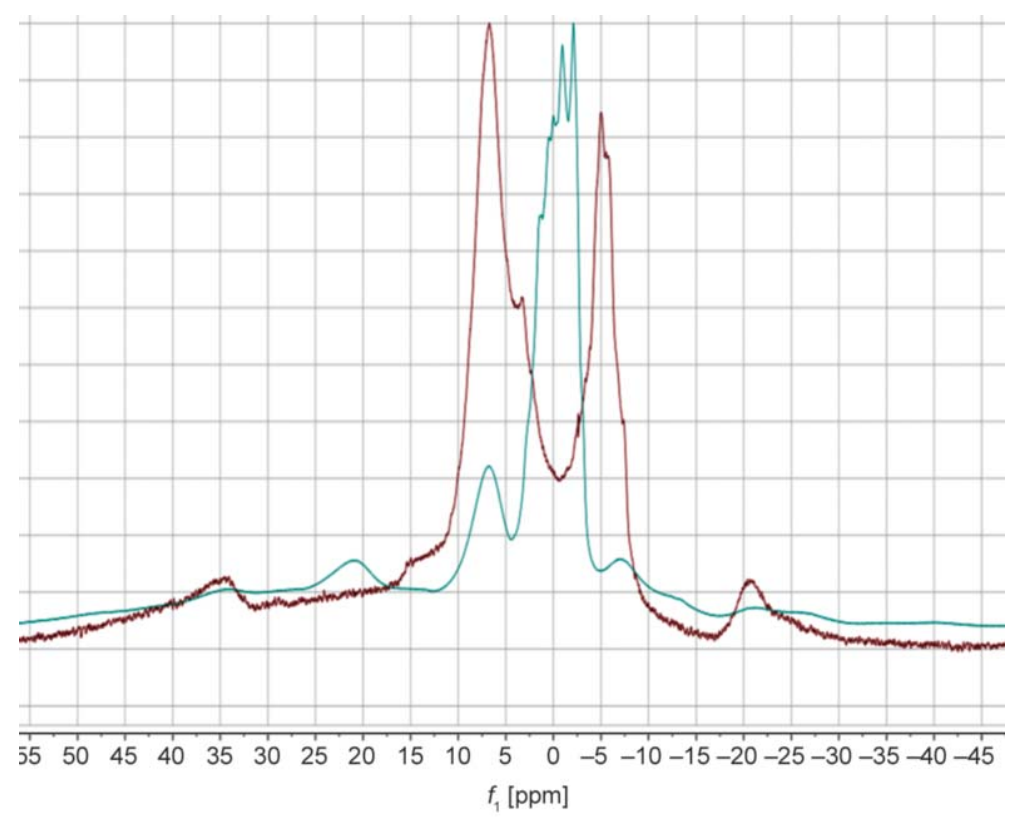

Figure 14. ${ }^{1} \mathrm{H}$ MAS NMR spectrum of hemin (red) and the resin cured with hemin (blue). Intensities of the signals of both spectra are in arbitrary units

The NMR solid spectra of the cured resin could help to elucidate in which spin state is the $\mathrm{Fe}(\mathrm{III})$. The $1 \mathrm{H}$ NMR spectrum of the pure hemin in solid state (Figure 13) resembles the one published by Villiers et al for ferriprotoporphyrin IX [Fe(III)PPIX] in aqueous solution which is characteristic of a five coordinate, high-spin Fe(III) [40, 41].

Some signals of the hemin are clearly distinguished in the final product but the high BADGE, $n=$ 0/hemin ratio prevents for a more detailed assignment of the signals (Figure 14). This makes almost impossible to differentiate between high and low spin states of $\mathrm{Fe}$ (III) and a direct measurement of the magnetic susceptibility is required. The strong signals around $0-5 \mathrm{ppm}$ belong to the protons of the cross-linked resin. The ratios of the hemin signals are maintained [40, 42-43].

The magnetic susceptibility $(\chi)$ of BADGE, $n=$ 0/hemin was studied by applying a DC current (Figure 15). The inverse of the susceptibility, $\chi^{-1}$, as a function of temperature (see insert) is linear, thus obeying the Curie-Weiss law. 


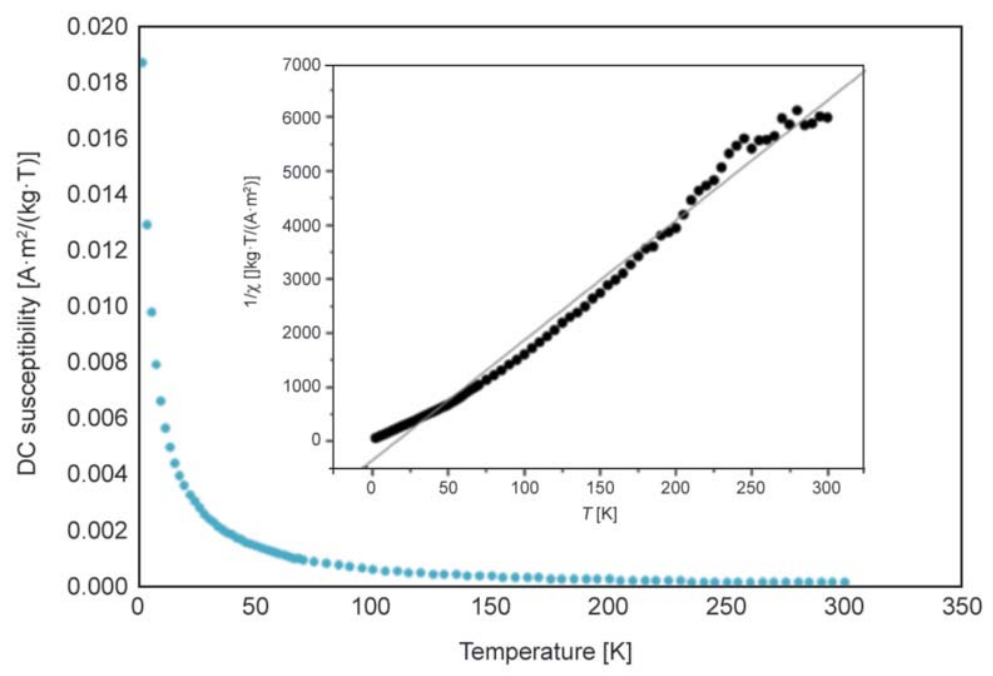

Figure 15. DC susceptibility and inverse susceptibility (insert) of BADGE, $n=0 /$ hemin as a function of temperature

From the linear fit of experimental results to Equation (3), values of 16.1 and 0.045 were obtained for the Weiss temperature, $\theta$, and the Curie constant, $C$, respectively:

$X^{-1}=C^{-1}(T-\theta)$

The Curie constant is related to the effective magnetic moment, $\mu_{\mathrm{eff}}$, by Equation (4):

$$
C=\frac{N \mu_{\mathrm{B}}^{2} g^{2} s(s+1)}{3 k_{\mathrm{B}}}, \quad \mu_{\mathrm{eff}}=\mu_{\mathrm{B}} g \sqrt{s(s+1)}
$$

where $\mu_{\mathrm{B}}$ is the Bohr magneton, $g$ is the Landé factor $(=2), k_{\mathrm{B}}$ is Boltzmann constant, and $N$ is the number of magnetic atoms per unit volume. The calculated value is $\mu_{\mathrm{eff}}=5.99 \mu_{\mathrm{B}}$, which perfectly agrees with

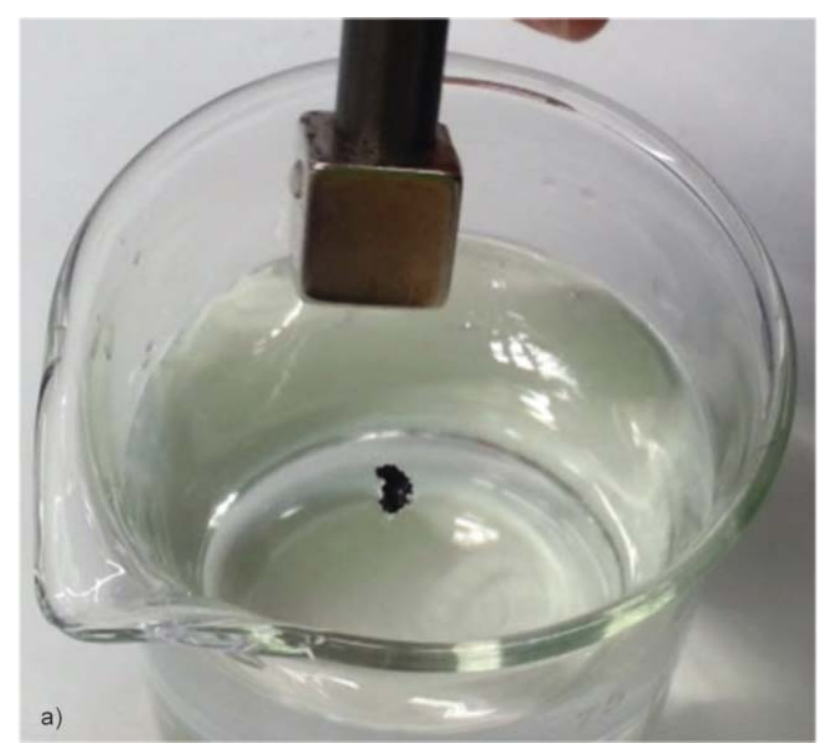

the theoretical value $\left(\mu_{\mathrm{eff}}=5.92 \mu B\right)$ for $S=5 / 2$ and with experimental values $\left(\mu_{\mathrm{eff}}=5.92-5.97 \mu_{\mathrm{B}}\right)$ published for pure hemin $[44,45]$. This agreement suggests that the $\mathrm{Fe}$ (III) remains in the high-spin state during the hemin-epoxy crosslinking reaction. At low temperatures $(T<20 \mathrm{~K})$, the susceptibility increases which can be associated with the strengthening of the magnetic short-range interactions, compatible with the positive value of Weiss paramagnetic temperature. For pure hemin, above $150 \mathrm{~K}$ (paramagnetic region), the susceptibility obeys the CurieWeiss law with a value of $31.76 \mathrm{~K}$ for the CurieWeiss temperature [46].

The modified resin with hemin, in the absence of friction, e.g., on the water surface, is attracted by a magnetic field (see Figure 16).

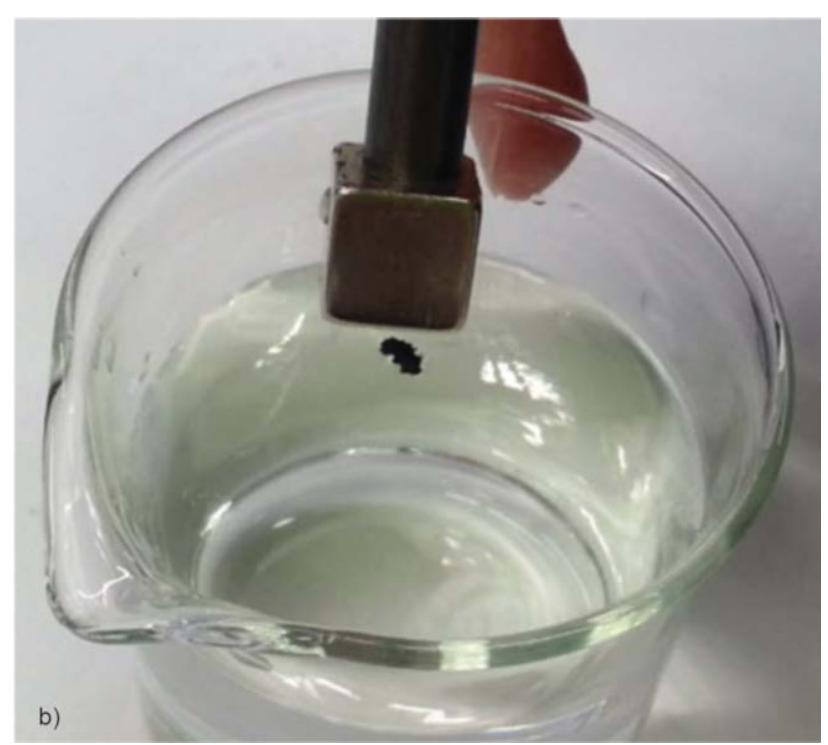

Figure 16. Behavior of the epoxy material in the presence of a magnetic field a) at $t=0, \mathrm{~b}$ ) after a few minutes 


\section{Conclusions}

The loss of the chlorine atom ligand during the cure of the resin allows that Fe(III) can act as Lewis acid catalyst for the crosslinking reactions. Consequently, at high BADGE, $n=0 /$ hemin ratios, the formation of ether and ester bonds occur simultaneously during the process.

On the other hand, the Fe(III) ion remains in the highspin state during the epoxy/hemin crosslinking reaction. As a result, the material exhibits the magnetic characteristics of hemin.

\section{Acknowledgements}

The authors thank the Ministerio de Ciencia y Tecnología, Spain, Project MAT2010-61721 for financial support. ECV also thanks Dr. Senén Paz and GAIRESA for a scholarship.

\section{References}

[1] Pascault J. P., Williams R. J. J.: General concepts about epoxy polymers. in 'Epoxy polymers. New materials and innovations' (eds.: Pascault J-P., Williams R. J. J.) WileyVCH, Weinheim, 1-12 (2010).

[2] Blank W. J., He Z. A., Picci M.: Catalysis of the epoxycarbonyl reaction. in 'International Waterborne, HighSolids and Powder Coatings Symposium, New Orleans, USA' 23/1-23/18 (2001).

[3] Fraga F., Castro-Díaz C., Rodríguez-Núñez E., Martínez-Ageitos J. M.: Kinetic analysis of relaxation process for the epoxy network diglycidyl ether of bisphenol A/ m-xylylenediamine. Journal of Applied Polymer Science, 96, 1591-1595 (2005). https://doi.org/10.1002/app.21602

[4] Fraga F., Penas M., Castro C., Rodríguez-Núñez E., Martínez-Ageitos J. M.: Cure kinetics of a diglycidyl ether of bisphenol a epoxy network $(n=0)$ with isophorone diamine. Journal of Applied Polymer Science, 106, 4169-4173 (2007). https://doi.org/10.1002/app.26989

[5] Abraham G., Packirisamy S., Vijayan T. M. Ramaswamy R.: Epoxy-imide resins from 2,2-bis[4-(4trimellitimidophenoxy)phenyl]propane: Adhesive and thermal properties. Journal of Applied Polymer Science, 88, 1737-1746 (2003).

https://doi.org/10.1002/app.11863

[6] Patel H. S., Panchal K. K.: Interacting blends of novel unsaturated polyester amide resin with styrene. E-Journal of Chemistry, 1, 32-37 (2004).

[7] Patel H. S., Panchal K. K.: Novel unsaturated polyester resins containing epoxy residues. International Journal of Polymeric Materials and Polymeric Biomaterials, 54, 1-7 (2005).

https://doi.org/10.1080/00914030390224247
[8] Singh D., Narula A. K.: Studies on the curing and thermal behaviour of diglycidyl ether of bisphenol-A (DGEBA) in the presence of aromatic diimide-diacids. Journal of Thermal Analysis and Calorimetry, 100, 199-205 (2010).

https://doi.org/10.1007/s10973-009-0089-1

[9] Brown J., Hamerton I., Howlin B. J.: Preparation, characterization, and thermal properties of controllable metal-imidazole complex curing agents for epoxy resins. Journal of Applied Polymer Science, 75, 201-217 (2001).

https://doi.org/10.1002/(SICI)1097-4628(20000110)75:2<201:: AID-APP2>3.0.CO;2-\#

[10] Hamerton I., Hay J. N., Howlin B. J., Jepson P., Mortimer S.: The development of controllable complex curing agents for epoxy resins. I. Preparation, characterization, and storage behavior of transition metal-diamine complexes. Journal of Applied Polymer Science, 80, 1489-1503 (2001). https://doi.org/10.1002/app. 1240

[11] Hamerton I., Hay J. N., Herman H., Howlin B. J., Jepson P., Gillies D. G.: The development of controllable complex curing agents for epoxy resins. II. Examining the dissociation and thermal behavior of transition metal-diamine complex-epoxy blends. Journal of Applied Polymer Science, 84, 2411-2424 (2002).

https://doi.org/10.1002/app.10530

[12] Ghaemy M., Rostami A. A., Omrani A.: Isothermal cure kinetics and thermodynamics of an epoxy-nickel-diamine system. Polymer International, 55, 279-284 (2006). https://doi.org/10.1002/pi.1949

[13] Yu H., Wang L., Huo J., Ding J., Tan Q.: Synthesis and curing behavior of a novel ferrocene-based epoxy compound. Journal of Applied Polymer Science, 110, 15941599 (2008). https://doi.org/10.1002/app.28584

[14] Vázquez E. C., Fraga F., Martínez-Ageitos J. M., Vázquez Tato J.: Curing kinetics of diglycidyl ether of bisphenol-A ( $n=0)$ using an iron-containing porphyrin as cross-linking agent. Journal of Applied Polymer Science, 130, 3972-3978 (2013).

https://doi.org/10.1002/app.39659

[15] Lojou E., Bianco P.: Electrocatalytic reduction of uranium by bacterial cytochromes: biochemical and chemical factors influencing the catalytic process. Journal of Electroanalytical Chemistry, 471, 96-104 (1999). https://doi.org/10.1016/S0022-0728(99)00255-7

[16] Bedioui F., Trevin S., Albin V., Guadalupe M., Villegas G., Devynck J.: Design and characterization of chemically modified electrodes with iron(III) porphyrinicbased polymers: Study of their reactivity toward nitrites and nitric oxide in aqueous solution. Analytica Chimica Acta, 341, 177-185 (1997). https://doi.org/10.1016/S0003-2670(96)00621-6 
[17] Younathan J. N., Wood K. S., Meyer T. J.: Electrocatalytic reduction of nitrite and nitrosyl by iron(III) protoporphyrin IX dimethyl ester immobilized in an electropolymerized film. Inorganic Chemistry, 31, 3280 3285 (1992).

https://doi.org/10.1021/ic00041a022

[18] de Groot M. T., Merkx M., Koper M. T. M.: Heme release in myoglobin-DDAB films and its role in electrochemical NO reduction. Journal of the American Chemical Society, 127, 16224-16232 (2005).

https://doi.org/10.1021/ja0546572

[19] Hayon J., Ozer D., Rishpon J., Bettelheim A.: Spectroscopic and electrochemical response to nitrogen monoxide of a cationic iron porphyrin immobilized in Nafioncoated electrodes or membranes. Journal of the Chemical Society, Chemical Communications, 1994, 619620 (1994).

https://doi.org/10.1039/c39940000619

[20] Lei J., Ju H., Ikeda O.: Supramolecular assembly of porphyrin bound DNA and its catalytic behavior for nitric oxide reduction. Electrochimica Acta, 49, 2453 2460 (2004).

https://doi.org/10.1016/j.electacta.2004.01.023

[21] Jiang R., Dong S.: Study on the electrocatalytic reduction of $\mathrm{H}_{2} \mathrm{O}_{2}$ at iron protoporphyrin modified electrode with a rapid rotation-scan method. Electrochimica Acta, 35, 1227-1232 (1990).

https://doi.org/10.1016/0013-4686(90)90054-4

[22] Gao Y., Chen J.: Electrocatalysis of carbon dioxide with hemin and hemin-coated latex. Journal of Electroanalytical Chemistry, 583, 286-291 (2005).

https://doi.org/10.1016/j.jelechem.2005.06.011

[23] Peteu S., Peiris P., Gebremichael E., Bayachou M.: Nanostructured poly(3,4-ethylenedioxythiophene)-metalloporphyrin films: Improved catalytic detection of peroxynitrite. Biosensors and Bioelectronics, 25, 19141921 (2010).

https://doi.org/10.1016/j.bios.2010.01.008

[24] Shigehara K., Anson F. C.: Electrocatalytic activity of three iron porphyrins in the reduction of dioxygen and hydrogen peroxide at graphite cathodes. The Journal of Physical Chemistry, 86, 2776-2783 (1982).

https://doi.org/10.1021/j100211a043

[25] Bashyam R., Zelenay P.: A class of non-precious metal composite catalysts for fuel cells. Nature, 443, 63-66 (2006).

https://doi.org/10.1038/nature05118

[26] Liang Z-X., Song H-Y., Liao S-J.: Hemin: A highly effective electrocatalyst mediating the oxygen reduction reaction. The Journal of Physical Chemistry C, 115, 2604-2610 (2011).

https://doi.org/10.1021/jp1112334

[27] Zvetkov V. L., Krastev R. K., Paz-Abuin S.: Is the Kamal's model appropriate in the study of the epoxyamine addition kinetics? Thermochimica Acta, 505, 47 $52(2010)$.

https://doi.org/10.1016/j.tca.2010.03.024
[28] Flammersheim H. J.: Typical sources of error in the kinetic analysis of models with pre-equilibria: DSC investigations of epoxide-amine curing reactions. Thermochimica Acta, 296, 155-159 (1997).

https://doi.org/10.1016/S0040-6031(97)00113-5

[29] Flammersheim H. J.: Kinetics and mechanism of the epoxide-amine polyaddition. Thermochimica Acta, 310, 153-159 (1998). https://doi.org/10.1016/S0040-6031(97)00225-6

[30] Swier S., Van Mele B.: Mechanistic modeling of the reaction kinetics of phenyl glycidyl ether (PGE) + aniline using heat flow and heat capacity profiles from modulated temperature DSC. Thermochimica Acta, 411, 149169 (2004).

https://doi.org/10.1016/j.tca.2003.08.009

[31] Swier S., Van Assche G., Van Mele B.: Reaction kinetics modeling and thermal properties of epoxy-amines as measured by modulated-temperature DSC. I. Linear step-growth polymerization of DGEBA + aniline. Journal of Applied Polymer Science, 91, 2798-2813 (2004). https://doi.org/10.1002/app.13466

[32] Swier S., Van Assche G., Van Mele B.: Reaction kinetics modeling and thermal properties of epoxy-amines as measured by modulated-temperature DSC. II. Network-forming DGEBA + MDA. Journal of Applied Polymer Science, 91, 2814-2833 (2004).

https://doi.org/10.1002/app.13467

[33] Zvetkov V. L., Krastev R. K., Samichkov V. I.: Rate equations in the study of the DSC kinetics of epoxyamine reactions in an excess of epoxy. Thermochimica Acta, 478, 17-27 (2008).

https://doi.org/10.1016/j.tca.2008.08.012

[34] Sbirrazzuoli N., Mititelu-Mija A., Vincent L., Alzina C.: Isoconversional kinetic analysis of stoichiometric and off-stoichiometric epoxy-amine cures. Thermochimica Acta, 447, 167-177 (2006).

https://doi.org/10.1016/j.tca.2006.06.005

[35] Vyazovkin S., Sbirrazzuoli N.: Isoconversional kinetic analysis of thermally stimulated processes in polymers. Macromolecular Rapid Communications, 27, 15151532 (2006).

https://doi.org/10.1002/marc.200600404

[36] Dell'Erba I. E., Williams R. J. J.: Homopolymerization of epoxy monomers initiated by 4-(dimethylamino)pyridine. Polymer Engineering and Science, 46, 351-359 (2006). https://doi.org/10.1002/pen.20468

[37] Weissbluth M.: Hemoglobin, cooperativity and electronic properties. Springer, New York (1974).

[38] Birdy R., Behere D. V., Mitra S.: Magnetic properties and electronic structure of high spin iron(III) porphyrins. The Journal of Chemical Physics, 78, 1453-1458 (1983). https://doi.org/10.1063/1.444888

[39] Hill H. A. O., Morallee K. G.: Nuclear magnetic resonance spectra of bis(pyridinato)iron(III)-protoporphyrin IX complexes. Journal of the American Chemical Society, 94, 731-738 (1972). https://doi.org/10.1021/ja00758a009 
[40] Wickramasinghe N. P., Shaibat M. A., Ishii Y.: Elucidating connectivity and metal-binding structures of unlabeled paramagnetic complexes by ${ }^{13} \mathrm{C}$ and ${ }^{1} \mathrm{H}$ solidstate NMR under fast magic angle spinning. The Journal of Physical Chemistry B, 111, 9693-9696 (2007). https://doi.org/10.1021/jp0727289

[41] de Villiers K. A., Kaschula C. H., Egan T. J., Marques H. M.: Speciation and structure of ferriprotoporphyrin IX in aqueous solution: Spectroscopic and diffusion measurements demonstrate dimerization, but not $\mu$-oxo dimer formation. Journal of Biological Inorganic Chemistry, 12, 101-117 (2007).

https://doi.org/10.1007/s00775-006-0170-1

[42] Dugad L. B., Mitra S.: Nuclear magnetic resonance of paramagnetic metalloporphyrins. Proceedings of the Indian Academy of Sciences - Chemical Sciences, 93, 295-311 (1984).

https://doi.org/10.1007/BF02840521
[43] Parra Y., Ferrer R. E., Montero K., Martinez M.: Spectroscopy of quinoline antimalarials drugs interactions with Fe(III)PPIX (in Spanish). Quimica Viva, 10, 154186 (2011).

[44] Sullivan S., Hambright P., Evans B. J., Thorpe A., Weaver J. A.: The magnetic susceptibility of hemin 303$4.5^{\circ} \mathrm{K}$. Archives of Biochemistry and Biophysics, 137, 51-58 (1970). https://doi.org/10.1016/0003-9861(70)90409-1

[45] Harris G.: Zero-field splitting, magnetic-field energies, effective magnetic moments, and electric-field gradients in high-spin ferric porphyrin compounds. The Journal of Chemical Physics, 48, 2191-2214 (1968).

https://doi.org/10.1063/1.1669413

[46] Bartoszek M., Balanda M., Skrzypek D., Drzazga Z.: Magnetic field effect on hemin. Physica B: Condensed Matter, 307, 217-223 (2001).

https://doi.org/10.1016/S0921-4526(01)00630-5 